\title{
Study on Hearing Impairment in Bangladesh
}

\author{
Mohammad Mahabubul Alam Chowdhury ${ }^{1 *}$ \\ Kamrul Hassan Tarafder ${ }^{2}$ \\ Pran Gopal Datta ${ }^{2}$ \\ Mostafa Zaman ${ }^{3}$ \\ Nasima Akhtar ${ }^{2}$ \\ Kawsar Sultana ${ }^{4}$
}

${ }^{1}$ Department of Otolaryngology and Head \& Neck Surgery Institute of Applied Health Sciences (IAHS) Chattogram, Bangladesh.

${ }^{2}$ Department of Otolaryngology \& Head-Neck Surgery Bangabandhu Sheikh Mujib Medical University (BSMMU) Dhaka, Bangladesh.

${ }^{3}$ Non-Communicable Disease Unit World Health Organization

Dhaka, Bangladesh.

${ }^{4}$ Department of Community Medicine Chattogram Maa-O-Shishu Hospital Medical College Chattogram, Bangladesh.

\footnotetext{
${ }^{*}$ Correspondence to:

Dr. Mohammad Mahabubul ALam Chowdhury Associate Professor

Department of Otolaryngology and Head \& Neck surgery Institute of Applied Health Sciences (IAHS)

Chattogram, Bangladesh

Mobile : +8801819320667

Email :mahbubulent@gmail.com
}

Date of Submission : 15.02 .2021

Date of Acceptance ： 26.02 .2021

www.banglajol.info/index.php/CMOSHMCJ

\begin{abstract}
Background : Hearing impairment is one of the leading causes of disability in Bangladesh. Since half the cases can be prevented through public awareness, early detection and timely management, planning of public health interventions become necessary. To achieve this, a nationwide level of evidence is required. This survey was conducted with the aim of determining the prevalence of hearing impairment in Bangladesh.
\end{abstract}

Materials and methods: The study was a cross-sectional one, conducted between January to May 2013, where a multistage, geographically clustered sampling approach was used. A total of 52 primary sampling units were selected, and from each unit households were selected at random followed by random selection of an individual from each household. In total, 5,220 people were targeted out of which data collection could be completed from 4260 individuals. (82\%). Following clinical assessment of study subjects, hearing status was assessed by pure tone audiometry and otoacoustic emission test.

Results : The mean age was 32 years among which $58 \%$ were females. Among men, there were $29 \%$ students, $28 \%$ agriculture workers and $14 \%$ business men. A major portion of females (63\%) were home makers. On clinical examination, $11.5 \%$ respondents had impacted ear wax, 6.2\% had chronic middle ear infections with eardrum perforation, and $5.3 \%$ had otitis media with effusion.On hearing assessment, $34.6 \%$ respondents had some form of hearing loss ( $>25 d B$ in better ear). Conductive hearing loss was found in $12.0 \%$, sensorineural in $4.5 \%$ and mixed in $3.8 \%$, where the latter two increased in prevalence with age. Out of the total respondents, 9.6\% had disabling hearing loss according to WHO criteria, with a higher prevalence in adults $>60$ years(37\%). Logistic regression analysis showed age, socioeconomic status, presence of ear wax, chronic suppurative otitis media, otitis media with effusion and otitis externa were significant predictors of disabling hearing loss.

Conclusion : The major causes of conductive hearing loss are chronic suppurative otitis media and otitis media with effusion.

Key words : Otitis media; Hearing loss; Effusion.

\section{INTRODUCTION}

The global burden of hearing impairment is rising in prevalence with about $15 \%$ of the world's population suffering from some form of hearing loss, many of whom are children below 15 years of age ${ }^{1}$. According to a 2013 report by the world health organization an estimated 360 million people suffered from disabling hearing loss among with 32 million were children ${ }^{2}$. This estimation is projected to rise in the near future with approximately $90 \%$ of the people with moderate to profound hearing loss residing in low- and middle-income countries. 
In Bangladesh, hearing impairment is the second most common form of disability that causes economic, social, educational and vocational problems for both the victims and the country at large. Factors such as maternal illness during pregnancy, ototoxic drugs, genetics, excessive noise over an extended period of time, aging, various diseases, etc. are responsible for hearing impairment. One small scale study done in 2002 reported hearing impairment in $7.9 \%$ of Bangladeshi people. A similar prevalence $(6.3 \%)$ was also found in India. When this impairment beings to affect a person's day to day activities and restricts their social life, it is termed as disabling hearing impairment. According to $\mathrm{WHO}$, an estimated $2.5 \%$ of disabling hearing loss was found in South Asian children below 15 years of age.

Since half of the hearing impairments can be prevented through awareness, early detection and treatment, emphasis should be placed on primary healthcare systems to reach out to potential victims. Although Bangladesh has a well-planned primary health care infrastructure, lack of representative data makes it difficult for planning intervention programs to tackle this problem. Hence, the present study has been conducted to determine the prevalence of hearing impairment in Bangladesh.

\section{MATERIALS AND METHODS}

This cross sectional study conducted between January to May 2013 that followed modified procedure by WHO for a population-based survey to enroll study subjects ${ }^{3}$. Samples were collected by multistage sampling.The target population were people of all ages residing in Bangladesh for an extended period of time. The sampling frame was the population census conducted by the Bangladesh Bureau of Statistics in 2011. The primary sampling units were mauza and mahallas (The smallest geographical units with defined boundaries), while the secondary sampling units were households defined as "a dwelling in which persons either related or unrelated living together and taking food from the same kitchen." 4 In the first stage, 52 primary sampling units were selected (11 urban and 41 rural). This was followed by random selection of secondary sampling units from the primary units. Finally, one person from each household (Secondary sampling unit) were selected at random. To evaluate hearing impairment in very young children otoacoustic emission was used. In children a little older observing behavior such as alertness, cessation of activity, widening of eyes or facial grimace were used to evaluate hearing status. In adults, tuning fork test was conducted to differentiate between conductive and sensorineural hearing loss. Here weber's Rinne's and absolute bone conduction tests were performed together. Pure tone audiometry was done in subjects older than 4 years old. tympanometry was used to diagnose middle ear disease and otoacoustic test was used to screen hearing in neonates and people who were sensitive to the other procedures.

Classification of hearing impairment was made according to WHO classification ${ }^{5}$. The categorization was as follows.

i) No impairment $(0-25 \mathrm{~dB})$

ii) Mild impairment $(26-40 \mathrm{~dB})$ iii) Moderate impairment (41-60 dB)

iv) Severe impairment $(61-80 \mathrm{~dB})$

v) Profound impairment $(>80 \mathrm{~dB})$

Disabling hearing impairment was defined as permanent unaided hearing threshold level for the better ear of $41 \mathrm{~dB}$ or greater (>30 dB in children younger than 15 years).

\section{RESULTS}

A total of 4,260 people were enrolled in this study. The mean age of respondents was 32 years with male: female ratio of 1:1.4. Among the subjects were 27 infants with an average age of 7 months (Table I).

Table I : Age and gender distribution of respondents.

\begin{tabular}{lrrr}
\hline Age group (Years) & Male $(\mathrm{n}=1774)$ & Female $(\mathrm{n}=2486)$ & Total \\
$0-4$ & $150(8.5 \%)$ & $120(4.8 \%)$ & $270(6.3 \%)$ \\
$5-14$ & $434(24.5 \%)$ & $465(18.7 \%)$ & $899(21.1 \%)$ \\
$15-29$ & $350(19.7 \%)$ & $596(24 \%)$ & $946(22.2 \%)$ \\
$30-44$ & $319(18 \%)$ & $616(24.8 \%)$ & $935(21.9 \%)$ \\
$45-59$ & $288(16.2 \%)$ & $451(18.1 \%)$ & $739(17.3 \%)$ \\
$60+$ & $233(13.1 \%)$ & $238(9.6 \%)$ & $471(11.1 \%)$ \\
\hline
\end{tabular}

Table II : Occupation of the respondents $(\mathrm{n}=3828)$.

\begin{tabular}{lcrrrrrrr}
$\begin{array}{l}\text { Age group } \\
\text { (Years) }\end{array}$ & $\begin{array}{c}\text { No } \\
\text { occupation }\end{array}$ & Student Agriculture & \multicolumn{3}{c}{$\begin{array}{c}\text { Business } \\
\text { worker }\end{array}$} & \multicolumn{5}{c}{$\begin{array}{c}\text { Industry } \\
\text { maker }\end{array}$} & $\begin{array}{r}\text { Homervices } \\
\text { sether }\end{array}$ \\
\hline $7-14$ & 26 & 699 & 4 & 4 & 2 & - & 3 \\
$15-29$ & 75 & 231 & 80 & 56 & 48 & 370 & 85 \\
$30-44$ & 23 & 13 & 121 & 94 & 64 & 521 & 104 \\
$45-59$ & 26 & - & 142 & 71 & 44 & 396 & 56 \\
$60+$ & 174 & - & 96 & 19 & 9 & 147 & 25 \\
Total & 324 & 943 & 443 & 244 & 167 & 1434 & 273 \\
\hline
\end{tabular}

On observing occupation of the respondents, majority were home makers, followed by students, agriculture workers, business, industry workers and other services. 324 respondents had no occupations with most of them in the $60+$ age group. In the table below 432 respondents were below 7 years of age and were hence excluded from this analysis (Table II).

Table III : Condition of the ear based on history and clinical examination $(\mathrm{n}=4260)$.

\begin{tabular}{lrrrrrrr}
$\begin{array}{l}\text { Age } \\
\text { group } \\
\text { (Years) }\end{array}$ & Norma** & $\begin{array}{r}\text { Wax } \\
\text { Foreign } \\
\text { body }\end{array}$ & $\begin{array}{r}\text { Otitis } \\
\text { externa } \\
\text { effusion }\end{array}$ & $\begin{array}{r}\text { Otitis } \\
\text { media with }\end{array}$ & $\begin{array}{r}\text { Acute } \\
\text { otitis media }\end{array}$ & $\begin{array}{r}\text { Chronic } \\
\text { otitis media }\end{array}$ \\
\hline $0-4$ & 171 & 86 & - & 5 & 3 & - & 5 \\
$5-14$ & 603 & 197 & 3 & 15 & 29 & 1 & 51 \\
$15-29$ & 814 & 59 & 1 & 5 & 29 & 2 & 36 \\
$30-44$ & 747 & 42 & 3 & 15 & 52 & 2 & 74 \\
$45-59$ & 555 & 49 & 1 & 8 & 52 & - & 64 \\
$60+$ & 304 & 56 & 3 & 13 & 61 & - & 34 \\
Total & 3194 & 489 & 11 & 71 & 226 & 5 & 264 \\
\hline
\end{tabular}

*No visible ear disease. 
From patient history and physical examination, no visible ear disease was observed in $75 \%$ of the respondents. However, on further evaluation of these normal subjects, hearing loss was identified in 228 individuals. Among the patients with visible ear diseases, the most common was ear wax, followed by Chronic Suppurative Otitis Media (CSOM) Otitis Media with Effusion (OME) otitis externa, presence of foreign body and finally acute suppurative otitis media (Table III).

Table IV : Status of hearing based on clinical assessment $(\mathrm{n}=4260)$.

\begin{tabular}{lccc}
$\begin{array}{l}\text { Age group } \\
\text { (Years) }\end{array}$ & Normal & $\begin{array}{c}\text { Hearing loss } \\
\text { in one ear }\end{array}$ & $\begin{array}{c}\text { Hearing loss } \\
\text { in both ears }\end{array}$ \\
$0-4$ & 235 & 12 & 23 \\
$5-14$ & 781 & 61 & 57 \\
$15-29$ & 856 & 54 & 36 \\
$30-44$ & 776 & 88 & 71 \\
$45-59$ & 552 & 73 & 114 \\
$60+$ & 217 & 57 & 197 \\
Total & 3417 & 345 & 498 \\
\hline
\end{tabular}

Status of hearing was clinically assessed by history, tuning fork test and observation of behavior or response to sound (Specifically in children less than 4 years of age). Out of all respondents, 3417 had normal hearing, 345 had hearing loss in one ear and 498 had hearing loss in both ears. About $40 \%$ of respondents with hearing loss in both ears belonged to the $60+$ age group. Additionally, $16 \%$ of respondents with hearing loss in both ears were children below 15 years of age (Table IV).

Table $\mathbf{V}$ : Type of hearing loss $(\mathrm{n}=3990)$.

\begin{tabular}{lrrrrr}
$\begin{array}{l}\text { Age group } \\
\text { (Years) }\end{array}$ & $\begin{array}{c}\text { Conductive } \\
\text { loss }\end{array}$ & $\begin{array}{c}\text { Mixed } \\
\text { loss }\end{array}$ & $\begin{array}{c}\text { Sensorineural } \\
\text { loss }\end{array}$ & $\begin{array}{c}\text { Clinically } \\
\text { normal hearing }\end{array}$ & Total \\
$5-14$ & 102 & 10 & 7 & 780 & 899 \\
$15-29$ & 74 & 9 & 8 & 855 & 946 \\
$30-44$ & 128 & 18 & 13 & 776 & 935 \\
$45-59$ & 112 & 36 & 38 & 553 & 739 \\
$60+$ & 62 & 79 & 112 & 218 & 471 \\
Residence & & & & & \\
Urban & 92 & 24 & 21 & 844 & 981 \\
Rural & 386 & 128 & 157 & 2338 & 3009 \\
Total & 478 & 152 & 178 & 3182 & 3990 \\
\hline
\end{tabular}

Table V illustrates the types of hearing loss among the respondents. Tuning fork test was done to identify the type of hearing loss. Children below 4 years of age $(n=270)$ had to be excluded from this table since, nature of hearing loss could not be clinically assessed in this age group. In the remaining 3990 people, $83 \%$ of the respondents with some form of hearing loss were from rural areas. Additionally, 31\% of the respondents with some form of hearing loss belonged to the $60+$ age group. Conductive hearing loss was the most common type followed by sensorineural loss and finally mixed type of hearing loss. Frequencies of both mixed and sensorineural types of hearing loss increased with increase in age.
Table VI : Degrees of hearing loss $(n=4260)$.

\begin{tabular}{|c|c|c|c|c|c|}
\hline $\begin{array}{l}\text { Age group } \\
\text { (Years) }\end{array}$ & $\begin{array}{l}\text { No loss } \\
(0-25 \mathrm{~dB})\end{array}$ & $\begin{array}{l}\text { Mild loss } \\
(26-40 \mathrm{~dB})\end{array}$ & $\begin{array}{l}\text { Moderate loss } \\
(41-60 \mathrm{~dB})\end{array}$ & $\begin{array}{l}\text { Severe loss } \\
(61-80 \mathrm{~dB})\end{array}$ & $\begin{array}{l}\text { Profound loss or } \\
\text { deafness }(\geq 81 \mathrm{~dB})\end{array}$ \\
\hline $0-4$ & 233 & 22 & - & - & 15 \\
\hline $5-14$ & 721 & 168 & 4 & 2 & 4 \\
\hline $15-29$ & 762 & 157 & 23 & 2 & 2 \\
\hline $30-44$ & 621 & 265 & 40 & 5 & 4 \\
\hline $45-59$ & 355 & 296 & 68 & 13 & 7 \\
\hline $60+$ & 96 & 204 & 123 & 31 & 17 \\
\hline Residence & & & & & \\
\hline Urban & 863 & 145 & 38 & 10 & 8 \\
\hline Rural & 1925 & 967 & 220 & 43 & 41 \\
\hline Total & 2788 & 1112 & 258 & 53 & 49 \\
\hline
\end{tabular}

The table above (Table VI) shows the degrees of hearing loss among the respondents. Profound loss or deafness was usually observed in children 4 years and below or in adults who were 60 years and above. Pure tone audiometry and otoacoustic emission test methods were used to find the degrees of hearing loss among respondents. The classification was done according to WHO hearing impairment guidelines. Pure tone audiogram was not done on children below 4 years of age and infants were assessed by otoacoustic emission tests and behavior observation.

Table VII : Respondents with disabling hearing loss $(n=4260)$.

\begin{tabular}{lcc} 
Age group (years) & Male & Female \\
$0-4(\geq 31$ dB hearing loss $)$ & 11 & 4 \\
$5-14(\geq 31$ dB hearing loss $)$ & 27 & 28 \\
$15-29(\geq 41$ dB hearing loss $)$ & 11 & 16 \\
$30-44(\geq 41$ dB hearing loss $)$ & 12 & 38 \\
$45-59(\geq 41$ dB hearing loss $)$ & 31 & 57 \\
$60+(\geq 41$ dB hearing loss $)$ & 77 & 95 \\
Residence & & \\
$\quad$ Urban & 25 & 38 \\
$\quad$ Rural & 144 & 200 \\
Total $\quad 169$ & 238 \\
\hline
\end{tabular}

Table VII describes the prevalence of disabling hearing loss according to age group of respondents and residential area. According to WHO, disabling hearing loss is defined as more than $40 \mathrm{~dB}$ in those aged 15 years and above, but more than $30 \mathrm{~dB}$ in children below this age. Over all, the prevalence was $9.6 \%$ (95\% CI between $8.5 \%$ to $10.8 \%$ ). Although no apparent difference in gender was observed, a variation across age groups were observed with increasing rates after 60 years of age.

Table VIII : Multiple Logistic regression analysis to identify significant risk factors for disabling hearing loss.

\begin{tabular}{lcccc} 
Variable & $\begin{array}{c}\text { Beta } \\
\text { coefficient }\end{array}$ & $\begin{array}{c}\text { Coefficient } \\
\text { error }\end{array}$ & p value & Odds ratio \\
Age & 0.05 & 0.00 & 0.00 & 1.1 \\
Family history & 0.35 & 0.18 & 0.05 & 1.4 \\
Wealth & -0.26 & 0.05 & 0.00 & 0.8 \\
Impacted wax & 0.98 & 0.18 & 0.00 & 2.7 \\
CSOM & 2.08 & 0.17 & 0.00 & 8.0 \\
OM with effusion & 1.54 & 0.18 & 0.00 & 4.7 \\
Otitis externa & 1.08 & 0.34 & 0.00 & 2.9 \\
\hline
\end{tabular}


Finally, amultiple logisticregression analysis was conducted using all the variables, namely; age, sex, residence, family history of hearing loss, history of consanguinity, wealth quartiles, wax, CSOM, OME, ASOM, otitis externa and foreign body. Only the ones that showed a significant $p$-value were retained in the final model. Table VIII displays the variablesthat were significant predictors of disabling hearing loss. These variables were age, socioeconomic status, presence of ear wax, chronic suppurative otitis media, otitis media with effusion and otitis externa.

\section{DISCUSSIONS}

This national survey is the first of its kind that used WHO methods to describe the prevalence of hearing impairment in Bangladesh. About one- fourth of Bangladeshi people suffered from some form of ear disease irrespective of hearing impairment. One third of all respondents had some form of hearing impairment while one tenth of all respondents had disabling hearing loss. If left uncorrected, hearing loss to this extent can hamper activities of daily living. Although no gender variation was observed in this study, age was found to be an important factor in predicting hearing impairment. Poverty was also found to have a relationship with disabling hearing loss; however, it cannot be confirmed if poverty lead to disabling hearing loss or vice versa.

One previous study done on Bangladeshi residents in 2002, reported a slightly lower rates of disabling hearing loss as compared to our study $(7.9 \% \text { vs } 9.6 \%)^{6}$. Nevertheless, incidences of any form of hearing losses were similar to our study. (34.2 vs $34.6 \%$ ). Hence, it is safe to state that prevalence of hearing loss remained almost in same for the past decade and little to no variation is expected without any new interference. No other studies consisting of relevant data from Bangladesh were found thus making further deductions difficult.

When comparing other countries in southeast Asia, prevalence of disabling hearing loss in our country was similar to that of India $(9.6 \% \text { vs } 9.8 \%)^{7}$. Prevalence reports from Nepal (15.3\%) and Sri Lanka $(21.7 \%)$ were much higher than our country ${ }^{8}$. Coming to an inference based on these studies need to be considered carefully since study designs and definitions for hearing impairment and disabling hearing loss were somehow different than our study. One prominent finding in our study was a drastic variation in the prevalence of disabling hearing loss in children 15 years of age and below. In our study, the prevalence was $6 \%$, almost two and a half times the collective estimate for southeast Asian region given by WHO. Rationally, this necessitates special focus on children in our country within this age group.

As per 2011 census, the total population of Bangladesh was 142 million $^{9,10}$. Among them, people suffering from ear diseases or hearing impairments are mentioned in the table above with some values being larger than the total population of many countries. Medical and surgical interventions including cochlear implantations are essential for millions of Bangladeshis since hearing losses such as mixed (5.4 million) or sensorineural (6.4 million) can ultimately lead to disability. These people need hearing aids while children of 4 years and below may need cochlear implants. Young children with deafness and hearing impairment suffer from delays in speech, language and cognitive skill development thus falling behind in school. Early detection and management are necessary to prevent permanent disability.

Table IX : Absolute number of people in Bangladesh suffering from ear disease and hearing loss.

$\begin{array}{lr}\text { Diseases or conditions (prevalence) } & \text { Absolute number in millions } \\ \text { Chronic suppurative otitis media (6.2\%) } & 8.8 \\ \text { Otitis media with effusion (5.3\%) } & 7.5 \\ \text { Impacted wax (11.5\%) } & 16.4 \\ \text { Any hearing loss (34.6\%) } & 49.2 \\ \text { Disabling hearing loss (9.6\%) } & 13.7 \\ \text { Profound hearing loss i.e., deafness (1.2\%) } & 1.7 \\ \text { Conductive hearing loss (12.0\%) } & 17.1 \\ \text { Mixed hearing loss (3.8\%) } & 5.4 \\ \text { Sensorineural hearing loss (4.5\%) } & 6.4\end{array}$

More than one third of the elderly population in Bangladesh have disabling hearing loss, a finding similar to studies in other populations ${ }^{11}$. Poor or absolutely no communication with surrounding people can lead to social exclusion, loneliness and frustration among these people. This could lead to work loss and hence poverty; another factor linked to disabling hearing loss in our study. In addition to these two factors, multiple logistic regression also showed that impacted ear wax, CSOM, OME and otitis external were independent predictors of disabling hearing loss. If left untreated, people suffering from OME may end up with ear drum perforation that could lead to life threatening conditions such as brain abscess and meningitis. Since otitis media is largely preventable and treatable, incorporating ear care to primary healthcare system for early detection and management of such cases can provide a cost effective and genuine solution.

\section{LIMITATION}

This survey was the inability to identify the role of exposure to chronic noise, ototoxic drugs and diabetes mellitus on hearing impairment. Other limitations included lack of sound proof rooms to conduct audiometry and lack of adequate post graduate specialists to conduct the tests. Nevertheless, efforts were made to keep the rooms as quite as possible to obtain proper results and research physicians were trained properly to conduct the tests. Infants were given a separate schedule to make them calm and quiet before otoacoustic emission was conducted.

\section{CONCLUSION}

Hearing impairment with disabling hearing loss is a common finding among Bangladeshi residents. Although the incidences of disabling hearing loss increases with age, the frequency is prominent even in children of 15 years and below. Treatable 
conditions of the ear such as presence of ear wax, chronic suppurative otitis media, otitis media with effusion and otitis externa were significantly associated with disabling hearing loss. Hence, early diagnosis, treatment and management of such cases can greatly reduce the number of people with hearing impairments.

\section{RECOMMENDATIONS}

As the afore mentioned conditions are easy to prevent and treat; and the fact that most cases are among people who are socioeconomically deprived, intervention programs to prevent hearing loss should be integrated with the primary healthcare systems. Furthermore, involving the educational system, to conduct hearing tests among school going children as a method of screening them can help detect and treat cases earlier, thus preventing permanent damage.
Hearing aids should be made accessible, affordable and available for people suffering from sensorineural or mixed type of hearing loss. Special attention should be given to the elderly population in this regard.

\section{DISCLOSURE}

All the authors declared no competing interest.

\section{REFERENCES}

1. World Health Organization. Global estimates on prevalence of hearing loss. Mortality and burden of disease. WHO 2012. Available at https://www.who.int/entity/pbd/deafness/estimates/WHO_GE_HL.PDF [Accessed on 4 August 2013]

2. World Health Organization. Global estimates on prevalence of hearing loss. [Internet]. Geneva: World Health Organization; 2012. Available from: http://www.who.int/pbd/deafness/estimates [Accessed 25 November 2013]

3. The department of international development (DFID). Disability, poverty and development. DFID, London. February 2000. Available at https://.handicap-international.fr/bibliographiehandicap/4PolitiqueHandicap/hand_pauvrete//DFID_disability.pdf [Accessed on 5 August 2013].

4. Non-Communicable Disease Unit, Director General of Health Services. National strategy on prevention of deafness and hearing impairment in Bangladesh: 2011-2016, Dhaka: DGHS, Ministry of Health. November 2011.

5. World Health Organization. Hearing measurement. Available at https://www.who.int/occupational_health/publications/noise8.pdf [Accessed on 4 August 2013].

6. Amin MN. Prevalence of hearing loss in Bangladesh [Report submitted to WHO Country Office for Bangladesh]. Dhaka, December. 2002.

7. Garg S, Chadha S, Malhotra S, Agarwal AK. Deafness: Burden, prevention and control in India. Natl Med J India. 2009;22(2):79-81.

8. World Health Organization. Deafness and hearing impairment survey. New Delhi: WHO SEARO. 2001.

9. Bangladesh Bureau of Statistics. Population and Housing census 2011. Preliminary result. Dhaka: Bangladesh Bureau of Statistics. 2011.

10. World Health Organization. Global health estimates. Available at https://www.who.int/healthinfo/global_burden_disease/ (Accessed on 4 August 2013).

11. World Health Organization. Millions of people in the world have hearing loss that can be treated or prevented. Available at https://www.who.int/pbd/deafness/news/Millionslivewithhearingloss.pdf (Accessed on 4 August 2013). 